\title{
Facile synthesis and characterizations of polypyrrole/BiOCl hybrid composites
}

\begin{abstract}
Polypyrrole( $(\mathrm{PPy}) / \mathrm{BiOCl}$ hybrid composites were synthesized for the first time via one-step chemical oxidation process by addition of $\mathrm{Bi}_{2} \mathrm{O}_{3}$ nanoparticle in an aqueous solution of pyrrole monomer/ $\mathrm{FeCl}_{3}$ oxidant agent. X-ray diffractions (XRD), field emission scanning electron microscopy (FESEM), and thermogravimetric technique confirmed the growth of $\mathrm{BiOCl}$ in PPy matrix. From the XRD, the amount of $\mathrm{BiOCl}$ in PPy matrix increased with increasing of $\mathrm{Bi}_{2} \mathrm{O}_{3}$ addition in pyrrole solution. The FESEM images indicated the presence of two phases related to $\mathrm{PPy}$ and $\mathrm{BiOCl}$. Thermal stability of $\mathrm{PPy} / \mathrm{BiOCl}$ hybrid composites has been improved in the range $300-800 \mathrm{~K}$ and degraded above $800{ }^{\circ} \mathrm{C}$, i.e., decomposition point of $\mathrm{BiOCl}$. Fourier transforms infrared spectroscopy point to a mutual interaction between PPy and $\mathrm{BiOCl}$ system. The characteristic optical absorption peaks of PPy shifted to higher wavelength in $\mathrm{PPy} / \mathrm{BiOCl}(5 \%)$ composites and disappeared at $\mathrm{PPy} / \mathrm{BiOCl}(20 \%)$. From electrical measurement, the $\mathrm{PPy} / \mathrm{BiOCl}$ hybrid composites have higher conductivity than $\mathrm{PPy}$, where the maximum conductivity observed was for $\mathrm{PPy} / \mathrm{BiOCl}(5 \%)$. The conducting mechanism of PPy and PPy/BiOCl composites followed three-dimensional Mott variable range hopping in the range of $300-150 \mathrm{~K}$ and has involved fluctuation-assisted tunneling phenomenon below $150 \mathrm{~K}$.
\end{abstract}

Keyword: Chemical synthesis; Polypyrrole; $\mathrm{BiOCl}$; Composites; Conductivity 